\title{
Smoking and the emergence of a stigmatized social status
}

\author{
Jennifer Stuber ${ }^{\mathrm{a}, *}$, Sandro Galea ${ }^{\mathrm{b}}$, Bruce G. Link ${ }^{\mathrm{c}}$ \\ ${ }^{a}$ University of Washington, Seattle, WA, USA \\ ${ }^{\mathrm{b}}$ University of Michigan, Ann Arbor, MI, USA \\ ${ }^{\mathrm{c} C o l u m b i a}$ University, New York, NY, USA
}

\section{A R T I C L E I N F O}

Article history:

Available online 16 May 2008

\section{Keywords:}

USA

Smoking

Stigma

Social norms

Tobacco control

\begin{abstract}
A B S T R A C T
An increase in the social unacceptability of smoking has dramatically decreased tobacco use in the USA. However, how policies (e.g., smoke free air laws) and social factors (e.g., social norms) drive the social unacceptability of tobacco use are not well understood. New research suggests that the stigmatization of smokers is an unrecognized force in the tobacco epidemic and could be one such mechanism. Thus, it is important to investigate the sources of smoker-related stigmatization as perceived by current and former smokers. In this study, we draw on the broader literature about stigma formation in the context of the tobacco epidemic and examine the role of attribution, fear, tobacco control policies, power and social norms in the formation of smoker-related stigma. We test hypotheses about the determinants of stigma using a population-based sample of 816 current and former smokers in New York City. The results show that perceptions of individual attributions for smoking behavior and fear about the health consequences of second hand smoke are important influences on smoker-related stigmatization. Structural forms of discrimination perpetrated against smokers and former smokers (e.g., company policies against hiring smokers) are also related to smoker-related stigma. Respondents with more education perceive more smoker-related stigma than respondents with less education and, Black and Latino respondents perceive less smoker-related stigma than White respondents. Social norms, specifically family and friends' expressed disapproval of smoking, contribute to the formation of smoker-related stigma. These findings suggest important points of leverage to harness the powerful role of stigma in the smoking epidemic and raise concerns about the possible role of stigma in the production of smoking disparities.
\end{abstract}

(c) 2008 Elsevier Ltd. All rights reserved.

\section{Introduction}

The increase in the social unacceptability of smoking has had a dramatic impact on tobacco use in the USA (Alamar \& Glantz, 2006) especially, in states and cities that have enacted tough tobacco control policies (Frieden et al., 2005; Gilpin, Lee, \& Pierce, 2004). However, how policies (e.g., smoke free air laws) and social factors (e.g., social norms) drive the social unacceptability of tobacco use are

\footnotetext{
* Corresponding author.

E-mail addresses: jstuber@u.washington.edu (J. Stuber), sgalea@ umich.edu (S. Galea), bgl1@columbia.edu (B.G. Link).
}

not well understood. Possible mechanisms underlying the link between social unacceptability and tobacco consumption include smoke free air in homes, workplaces and restaurants, media campaigns stressing the dangers of second hand smoke, and social norms (see Fichtenberg \& Glantz, 2002 as exemplar). A recent study suggests that the stigmatization of smokers may be another mechanism finding that smokers who perceive high levels of stigma are more likely be quitters (Stuber, Galea, \& Link, submitted for publication). In this paper, we examine the factors that contribute to perceptions of stigma among current and former smokers using newly developed measures of smokerrelated stigma. 
We conceptualize stigma as the negative labels, pejorative assessments, social distancing and discrimination that can occur when individuals who lack power deviate from group norms. Stigma is at once a social process of marginalization perpetrated by those who do the stigmatizing and at the same time a condition that stigmatized individuals must navigate. In this study, we focus on stigma perceived by current and former smokers, the persons who are stigmatized. To identify possible social and historical processes that may be at work in the construction of the smoker as pariah, we survey the broader literature on stigma formation in the context of the tobacco epidemic focusing on five theoretical domains as they relate to stigma: attribution theory and stigma, fear or peril and stigma, policy and stigma, power and stigma, and social norms and stigma.

\section{Attribution theory and stigma}

Attribution theory contends when a person is encountered who violates group norms, people attempt to search for the cause of this violation, which in turn, affects their reactions towards that person (Weiner, 1995). The theory predicts that stigmatized conditions believed to be outside the control of the stigmatized person (e.g., a person with HIV/AIDS who contracted the illness due to a blood transfusion) are associated with less blame and anger and with more positive emotions, which in turn leads to an inclination to help rather than to punish (Corrigan, 2000). Following this rationale, perceptions about the causes of smoking may be central to the formation of smoker-related stigma. For most of the 20th century, smoking was regarded as a socially learned habit and as a personal choice. Drawing from attribution theory, we expect that beliefs to this effect will be directly related to perceptions of smoker-related stigma.

Within the last decade our focus on other potential causes of smoking has emerged. Specifically, the role of social stress in causing and sustaining smoking behavior is beginning to be more widely accepted (Jarvis, 2004). We expect that the perception that smoking is caused by stress will be inversely related to smoker-related stigma because the locus of control for the behavior is reframed as determined by external circumstances. Support is also growing for the idea that there is an inherited vulnerability to nicotine addiction (Zickler, 2006). Attribution theory would predict that genetic causal attributions would decrease smoker-related stigma because the shift of control for the behavior is reframed as biological. However, research by Phelan (2005) on mental illness stigma suggests that genetic attributions not only fail to reduce stigmatizing beliefs but also actually contribute to increases in some stigma-relevant domains. She argues that because genetic characteristics are seen as irrevocable, genetic essentialist thinking leads to greater stigmatization when applied to negative valued qualities because it contributes to perceptions that the person is fundamentally different from others, that the problem is persistent and serious, and that the problem is likely to occur in other family members. Thus, we hypothesize genetic attributions for smoking will be positively related to smoker-related stigma.

\section{Fear and stigma}

Fear has been shown to contribute to stigmatizing attitudes towards numerous attributes, health conditions and behaviors such as leprosy (Bainson \& Van den Borne, 1998), HIV/AIDS (Herek, Capitanio, \& Widaman, 2002) and mental illness (Link, Phelan, Bresnahan, Stueve, \& Pescosolidio, 1999). The reasons underlying these fears (e.g., contagion, unpredictability) and the evidence base for them vary for each condition and behavior. Fear about the harms caused by second hand tobacco smoke may be one factor underlying smoker-related stigmatization. Mounting evidence in the 1970s, 1980s and 1990s indicated that smoking is not only a health hazard to smokers, but is also a health hazard to non-smokers. The effectiveness of the second hand smoke movement is emboldened by recognition of the innocent victim such as children with smoking mothers (Brandt, 1998). Thus, we hypothesize that fear about the threat second hand smoke poses to children will be positively related to perceptions of stigma.

\section{Policy and stigma}

The broader literature on social stigmatization identifies two ways that social policy can contribute to stigmatization. First, social policy has been shown to contribute to stigmatization through structural or institutional forms of discrimination. Structural discrimination includes the policies of private and governmental institutions that restrict the opportunities of marginalized groups whether such restriction occurs through intended or unintended consequences of those policies. There are numerous examples of social policy leading to the perpetuation of discrimination and to an increase in stigma perceived by persons of minority race/ethnicity, persons with HIV/AIDS and persons with mental illness (Corrigan, Markowitz, Watson, Rowan, \& Kubiak, 2003). Examples of structural discrimination are beginning to emerge in the context of the tobacco epidemic. For example, the American Civil Liberties Union (1998) reports atleast 6000 companies refuse to hire smokers including Alaska airlines, Union Pacific and the World Health Organization. These policies, by sanctioning discrimination, abrogate smoker's rights as "ordinary citizens" by placing "them" in a category that separates smokers from "us" (non-smokers). Our intent here is not to equate what we are calling structural discrimination perpetrated against smokers with structural discrimination perpetrated against other marginalized groups because there are ways in which the former instances of structural discrimination may be justified, for example, with rationales such as employers have to pay more for the health insurance of their smoking employees. Instead, what we are hypothesizing is that the process of separate and lower placement that results from this sort of policy will be positively associated with perceptions of smoker-related stigma among current and former smokers.

A second way that social policies lead to increased stigmatization is through symbolic messages of moral condemnation (Schneider \& Ingram, 1993). Policies designed to punish or segregate a designated group of individuals from others may be particularly stigma generating. By 
this logic, smoke free air laws may also produce stigma. Although smoke free air laws are imposed on the act of smoking and not on a smoker as an undesirable type of person, one need only look outside at the huddle of smokers commonly seen outside public buildings in inclement weather to witness the decreased social standing of smokers relative to non-smokers. Smoke free air laws are proliferating in the USA. By 2007, 49 states restricted smoking in government worksites, 39 sites restricted tobacco use in private workplaces, and forty one states placed restrictions on smoking in restaurants (American Lung Association, 2007). It is not just government that is regulating tobacco behavior. Private industry is also involved in tightening restrictions on workplace smoking (Brownson, Eriksen, Davis, \& Warner, 1997) and restrictions on smoking within households are also increasing (US Department of Health and Human Services, 1999). We hypothesize that smokers and former smokers who have greater exposure to (and awareness of) smoke free air laws will be more likely to perceive smoker-related stigma.

\section{Power, marginalization and stigma}

Link and Phelan (2001) argue that it is not possible to fully stigmatize, that is to successfully label, pejoratively stereotype, effectively set apart and broadly discriminate against, a particular group unless they lack social, economic or political power relative to the persons who are doing the stigmatizing. From this vantage point, one might argue that the stigmatization of the American smoker has been more smoothly achieved because the socioeconomic composition of smokers has changed in the USA in the last quarter century. The tobacco literature identifies a strong negative relationship between lower educational levels and income, blue collar work, and smoking cessation suggesting there is a strong social contextual component to smoking cessation (Barbeau, Krieger, \& Soobader, 2004). While socioeconomic disparities in smoking cessation are not well understood, several factors conceivably linked to stigmatization have been suggested. For example, studies have shown that blue collar workers reside in occupational environments that are less supportive of quitting (Sorenson, Emmons, Stoddard, \& Linnan, 2002). A recent study finds that cigarette smoking is related to differences in culture tastes between high socioeconomic and low socioeconomic individuals (Pampel, 2006). Thus, we hypothesize that persons of lower socioeconomic status will be less likely to perceive smoker-related stigma than individuals of higher socioeconomic status.

\section{Social norms and stigma}

We define social norms as rules or standards that are understood by members of a group, and that guide and/ or constrain social behavior even without the force of law. Stigma theorists point to the centrality of social norms to stigma formation processes. For example, Goffman (1963) argues that stigmatization is a general feature of any society because deviations from social norms are unavoidable and pervasive. Others write that stigmatization is a feature of all societies to extract conformity with social norms, which is necessary to enforce law and order. According to this view, stigmatization is a consequence for failing to comply with social norms for the purpose of making the deviant person conform and rejoin the group (Braithwaite, 1989) or to clarify for other members of the group the behaviors that are unacceptable and the consequences that will affect those who engage in those behaviors (Erikson, 1966). Stigma can only be used in these ways to increase conformity around behaviors and identities that are believed to be voluntary. Thus, we suspect social norms may be especially pertinent to understanding smoker-related stigma.

The task of thinking about how social norms might generate smoker-related stigma is complex because several different types of normative influences exist and they operate at multiple levels in individual's lives. In this study, we delineate two types of social norms. First, are descriptive norms, or the norms of "is", which are perceptions of what most people do in a particular situation (Cialdini, Kallgren, \& Reno, 1991). Second, are a set of social norms that are based not on what other people do, but on a set of normative beliefs: whether particular referents approve or disapprove of the behavior and how motivated the individual is to comply with each of these referents (Fishbein \& Ajzen, 1975). These norms have been referred to as the norms of "ought" or as injunctive norms (Cialdini et al., 1991). Of these two norm types, we suspect injunctive norms will be the most relevant to stigma formation processes because they are explicitly normative and judgmental whereas, descriptive norms are formulated based on observations of how often group norms are violated.

The relationship between social norms and smokerrelated stigma is further complicated by the fact that individuals are engaged in multiple social groups. Within each group, individuals are likely to encounter both injunctive and descriptive normative influences. Membership in some groups will undoubtedly be more important to individuals than membership in other groups. For example, adults will likely value the opinions of their family and friends more than they value the views of their neighbors although this may not always be the case. Thus, we hypothesize that individual's perceptions of injunctive norms operating at the family and peer level will have a more powerful influence on smoker-related stigma than injunctive norms perceived at the neighborhood level.

\section{Hypotheses of the present study}

We test the following hypotheses across our five theoretical domains in a sample of current and former smokers: (1) individual attributions of responsibility for smoking as well as genetic attributions are positively related to smoker-related stigma whereas, social attributions of responsibility for smoking are negatively related to smokerrelated stigma; (2) the fear that smoking poses a health threat to children is positively associated with smokerrelated stigma; (3) prior experiences of discrimination and greater exposure to smoke free air laws are positively related to smoker-related stigma; (4) education and income are positively related to smoker-related stigma.; and (5) injunctive norms operating at the family and peer 
level are more strongly associated with smoker-related stigma than injunctive norms operating at the neighborhood level, and injunctive norms operating at both the family/peer level and the neighborhood levels are more strongly associated with smoker-related stigma than descriptive norms operating at either of these levels.

\section{Methods}

\section{Study design and data collection}

This study was based on survey questions administered as part of the New York Social Environment Study (NYSES). The NYSES was a cross-sectional random digit dial telephone survey of 4000 New York City residents aged 18 years or older conducted between June and December 2005 and was run out of the University of Michigan. It was designed to assess the relationship between neighborhood characteristics and drug use behavior (including tobacco, alcohol and illicit drug use). Interviews were conducted in English, Spanish, Mandarin and Cantonese by trained interviewers using translated and back-translated questionnaires and a computer-assisted telephone interview system. An adult in each household was randomly selected by choosing the adult whose birthday was closest to the interview date. Up to 10 attempts were made to conduct the interview. The NYSES response rate among those eligible was 54\%, which is typical for RDD telephone studies in large densely populated urban areas (Galea et al., 2003). Comparisons of the NYSES sample to the U.S. census reveal that the sample is representative of NYC residents with respect to age, gender and racial/ethnic background (data not shown).

The findings for this study were based on responses from 816 current smokers and former smokers who quit since January 2002. Because this study probed a new area of inquiry, funding was limited. Within the confines of the study's resources, we decided to limit our sample to current and former smokers who quit since the enactment of NYC's relatively aggressive tobacco control laws (and did not collect data from all former smokers). Beginning in January 2002, New York City enacted some of the most aggressive tobacco control policies in the nation including a $\$ 1.50$ per pack increase on a pack of cigarettes and in January 2003 the smoke free air law was expanded to include all restaurants and bars (Frieden et al., 2005). We expected that former smokers who quit since January 2002 would be particularly exposed to stigma formation processes.

\section{Measures}

\section{Dependent variable}

Because there were no extant measures of smoker-related stigma available in the literature, questionnaire items measuring stigma related to being a smoker were developed from a widely used 12-item scale designed to assess perceived devaluation and discrimination related to mental illness among consumers of mental health treatment and the general public (Link, Cullen, Frank, \& Wozniak, 1987; Link \& Phelan, 2001). The measure assesses respondent perceptions of what most other people believe. Modification of these items was necessary to frame them in terms of smoking. For example, the item "Most people think less of a person who has been in a mental hospital" was modified to, "Most people think less of a person who smokes". To maintain the survey at a reasonable length, we pared down the number of items we could use to assess stigma to five. We pre-tested the survey on 20 participants randomly selected from NYC and elicited from these participants commentary about the questions. We refined the survey after the pre-testing phase of the study.

To derive the final smoker-related stigma measure, we specified a varimax orthogonal factor rotation for a factor analysis on the five items. Four of the five items loaded on one factor and had factor loadings of 0.32 or greater, which reflects at least $10 \%$ overlapping variance (Comrey \& Lee, 1992). Cronbach's $\alpha$ statistic was used to assess the reliability of the retained items as a scale $(\alpha=0.61)$. Responses to each component question were on a four-point Likert scale that ranged from strongly disagree to strongly agree. We created a summary score of these four items and divided it into tertiles representing: low, medium and high stigma.

\section{Independent variables}

Attribution and stigma. To assess what respondents believe were the causes of smoking we asked, "Smoking is caused by [ITEM]"? substituting weak character, bad genes and stress as possible response choices. The response categories to these questions and for all other questions described below except where indicated were strongly agree, somewhat agree, somewhat disagree or strongly disagree. In order to simplify the presentation of these data about these items we dichotomized each such that strongly agree and somewhat agree categories were coded as 1 and somewhat disagree and strongly disagree were coded as 0 . However, we also conducted analyses without dichotomizing the items and obtained the same pattern of results reported below.

Fear and stigma. To assess fear related to the health hazards posed by smoking we asked respondents if "Parents who smoke are a threat to their children." We included a variable to assess if respondents are the parent or primary caretaker of at least one child in the household under 18 years.

Policy and stigma. We created a measure of self-reported discrimination by asking respondents if any of the following things ever happened to them because of their smoking (yes or no)?: (1) You had difficulty renting an apartment or finding housing; (2) You were turned down for a job for which you were qualified; and (3) You were refused or charged more for health insurance because of your smoking.

In the survey, we asked respondents about their exposure to smoke free air laws in their home, in their workplace and in bars in their neighborhood. The same question wording and response categories were used for each. For example, to assess respondent exposure to smoke free air laws at home we asked the question, "Which statement best describes smoking in your home: People smoke 
anywhere inside your home, people smoke in some rooms or at some times, or people do not smoke anywhere inside your home?" Respondents who answered, "People do not smoke anywhere inside my home" were coded with a score of 1 indicating they were exposed to a smoke free air law at home whereas all other responses were coded as 0 . We used an identical coding scheme to assess exposure to smoke free air laws in one's workplace and in bars. For these questions, we also had to account for individuals who were not currently employed or who do not go to bars. These individuals received a 0 indicating no exposure. A summary score of these three items was created to reflect one's cumulative exposure to smoke free air laws.

Power and stigma. Socioeconomic status was assessed by educational level (coded as less than high school, high school or GED, some college or college graduate, and graduate school) and by individual-level income (measured continuously and in tertiles: less than $\$ 40,000, \$ 40,000$ $\$ 80,000, \$ 80,000+$ and missing).

Social norms and stigma. Four questions were used to assess social norms. To measure descriptive and injunctive norms at the family and peer level the following two questions were asked: "How many of your close friends or family would you say smoke cigarettes? Would you say all of them, some of them, a few of them or none of them." To assess the injunctive family/peer norm the question was asked, "How do most of your close friends or family feel about cigarette smoking among adults? Would you say that think it is acceptable, unacceptable, or that they don't care one way or the other?". Comparable questions were developed to assess descriptive and injunctive norms at the neighborhood level. Because we are interested in individual's perceptions of the norms in his/her neighborhood as opposed to an objective assessment of neighborhood norms based on an aggregated response, the measures of family and peer-level norms are not independent of the neighborhood-level norms.

Control variables. Racial/ethnic status was assessed by selfidentification and collapsed into the following four categories: White, Black, Hispanic/Latino or other. Age was assessed both as a continuous variable and coded into three categories (18-34, 35-54, 55+ years). Marital status was coded as married, divorced/separated or widowed, and never married and gender was also a control. We also control for self-reported current smoking status where 0 is current smoker and 1 is recent quitter.

\section{Statistical analyses}

We present the prevalence of smoker-related stigma perceived by smokers and former smokers who quite since January 2002. Bivariate analyses assessed the relationship between each of the variables described above and our measure of smoker-related stigma. We then constructed a polychotomous regression model to compare respondents who perceived low stigma to those who perceived high stigma and respondents who perceived medium stigma to those who perceived low stigma. All of the variables significant in the bivariate analyses at the $P<0.10$ level were included in this model. We weighted the sample by the probability of persons and telephones in household; SUDAAN was used to analyze the data to appropriately handle standard errors with survey weights.

\section{Results}

Fig. 1 shows the prevalence of perceived stigma among current and former smokers who quit since January 2002. Most respondents agreed that "Most people would not hire a smoker to take care of their children" (81\%) and that "Most non-smokers would be reluctant to date someone who smokes" (72\%). The prevalence of the perception "Most people believe smoking is a sign of personal failure" (21\%) and, "Most people think less of a person who smokes "(39\%), were endorsed less frequently but still indicate substantial stigma. The first two items measure social distance from smokers, whereas the second two items are measures of the devaluation of smokers. It could be argued the items, "Most people would be reluctant to date someone who smokes" and "Most people would not hire a smoker to take care of their children" are rational responses because of the harms posed by smoking and are not measures of stigma per se. Because these questions are being asked of former and current smokers and thus, may imply that smokers will act in ways that endanger others likely explains why these items load cohesively into one factor with the other two measures.

Table 1 reports bivariate associations that support many of our hypotheses. Concerning the attribution hypothesis respondents who perceived high levels of stigma were more likely to indicate that smoking was caused by weak character $(P<0.01)$ and by bad genes $(P=0.01)$ compared to respondents who perceive low or medium levels of stigma. Surprisingly, the belief that smoking was caused by stress was also positively associated with stigma $(P<0.01)$. In support of the fear hypothesis, we found that respondents who perceived medium and high levels of stigma were more likely to endorse the belief that parents who smoke were a threat to their children $(P<0.01)$. Contrary to what we expected, current and former smokers who were parents were less, not more likely to perceive smoker-related stigma $(P=0.02)$.

We also found support for the idea that social policies exacerbate smoker-related stigma. Respondents who experienced one or more forms of discrimination were more likely to perceive high levels of smoker-related stigma $(P=0.05)$. Contrary to what we expected, respondents who had greater exposure to smoke free air laws reported lower levels of smoker-related stigma compared to individuals who had less exposure to smoke free air laws $(P=0.02)$.

There was support for our power and marginalization hypothesis. Specifically, respondents with higher levels of education were more likely to perceive medium and high levels of stigma compared to respondents with less education $(P<0.01)$.

With respect to social norms and stigma, respondents who reported that family and friends found smoking unacceptable were more likely to perceive high stigma than 


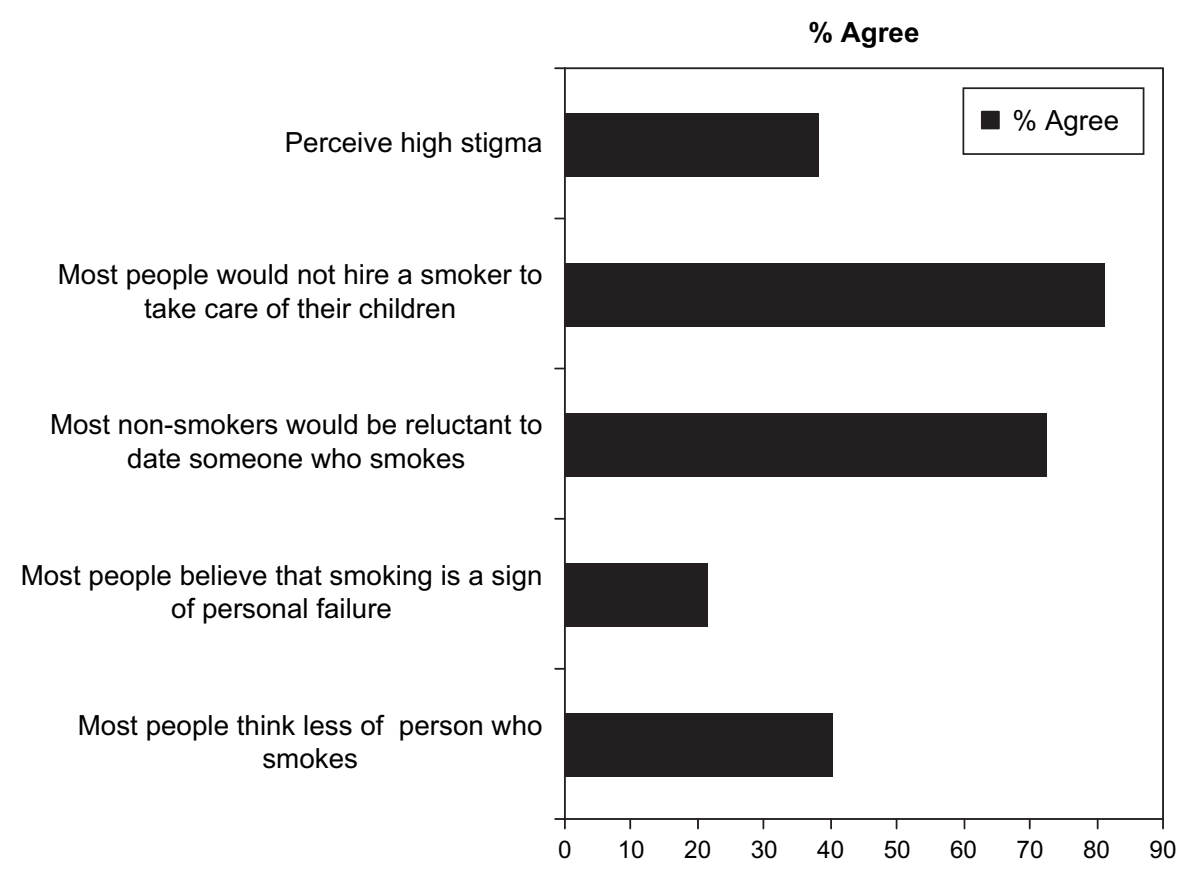

Fig. 1. Prevalence of perceived stigma $(N=816)$.

respondents who reported that family and friends find smoking acceptable and, there was an insignificant relationship between injunctive norms perceived at the neighborhood level and smoker-related stigma. However, descriptive norms at the neighborhoods level were associated with smoker-related stigma. Respondents who indicated that all or most individuals in their neighborhood smoked reported lower levels of perceived stigma compared to individuals who report that some or few or none of the people in their neighborhood smoke. Also of interest, Blacks and Latinos perceived less smoker-related stigma than Whites.

Most of these results were consistent in multivariate analyses comparing respondents who perceive high stigma to those who perceive low stigma and respondents who perceive medium stigma to those who perceive low stigma (see Table 2). The variables, "Smoking is caused by bad genes", respondent's cumulative exposure to smoke free air laws and descriptive neighborhood norms were no longer related to smoker-related stigma.

\section{Discussion}

Using data from a general population survey of New York City residents, we showed that current and former smokers who quit since January 2002 perceive substantial stigma and identified several factors that potentially contribute to this stigma. We found that (a) perceptions of individual attributions for smoking behavior, (b) fear that second hand smoke harms children, (c) structural forms of discrimination perpetrated against smokers, (d) low levels of education, and (e) social norms specifically, the normative evaluations of family and friends contribute to the formation of smoker-related stigma. To our surprise,
White respondents in our sample perceived more smoker-related stigma than Black or Latino respondents. In this discussion, we describe the limitations of this study and situate the results within the current tobacco epidemic organized by our five theoretical domains of stigma sources.

\section{Potential limitations}

First, stigma is not simply, or even primarily, generated from the attitudes of the population that is stigmatized, but also from those who share their community. In this work, we studied the determinants of stigma only among current and former smokers who quit since January 2002 in NYC. Although this moves us towards understanding the factors that drive perceived stigma in these groups, we can draw limited insight from this work about population-level determinants of stigmatizing attitudes and behavior. Thus, future research should assess the sources of smoker-related stigma in a population sample that includes non-smokers. Nonetheless, we underscore the importance of understanding the sources of smoker-related stigma in current and former smokers because this stigmatization is likely one of the social processes contributing to reduced smoking prevalence in the USA. Second, although this sample is representative of current smokers and of former smokers who quit since January 2002 in NYC, the results can only be generalized to all current and former smokers with caution. It is possible that our results overestimate the prevalence of stigma and had we included all former smokers the prevalence of stigma would be lower. It is also possible that the results related to tobacco control policies as determinants of stigma may be different had we surveyed all former smokers. Specifically, the relationship between perceived 
Table 1

Differentiating characteristics between current smokers and smokers who quit since January 2002 who perceive high stigma versus medium versus low stigma

\begin{tabular}{|c|c|c|c|c|c|c|c|c|c|}
\hline & \multicolumn{2}{|c|}{$\begin{array}{l}\text { Total } \\
(N=816)\end{array}$} & \multicolumn{2}{|c|}{$\begin{array}{l}\text { Low stigma } \\
(N=222)\end{array}$} & \multicolumn{2}{|c|}{$\begin{array}{l}\text { Medium } \\
\text { stigma }(N=280)\end{array}$} & \multicolumn{2}{|c|}{$\begin{array}{l}\text { High stigma } \\
(N=314)\end{array}$} & \multirow[t]{2}{*}{$P$-value } \\
\hline & $N$ & $\%$ & $N$ & $\%$ & $N$ & $\%$ & $N$ & $\%$ & \\
\hline \multicolumn{10}{|l|}{ Attribution hypothesis } \\
\hline Smoking is due to weak character & 133 & 18 & 22 & 12 & 25 & 9 & 86 & 31 & $<0.01$ \\
\hline Smoking is due to bad genes & 87 & 11 & 16 & 9 & 23 & 8 & 48 & 17 & 0.01 \\
\hline Smoking is due to stress & 578 & 72 & 134 & 60 & 209 & 76 & 235 & 76 & $<0.01$ \\
\hline \multicolumn{10}{|l|}{ Fear hypothesis } \\
\hline Parent or primary caretaker & 322 & 42 & 100 & 51 & 118 & 42 & 104 & 37 & 0.02 \\
\hline Parents who smoke are a threat to their children & 573 & 71 & 132 & 59 & 200 & 74 & 241 & 78 & $<0.01$ \\
\hline \multicolumn{10}{|l|}{ Policy hypothesis } \\
\hline Perceives one or more events of discrimination & 134 & 17 & 30 & 15 & 42 & 14 & 62 & 22 & 0.05 \\
\hline Exposure to household smoke free air & 400 & 51 & 101 & 49 & 142 & 52 & 157 & 52 & 0.71 \\
\hline Exposure to work-place smoke free air & 412 & 49 & 96 & 42 & 148 & 53 & 168 & 51 & 0.06 \\
\hline $\begin{array}{l}\text { Exposure to smoke free air laws in neighborhood bars } \\
\text { Smoke free air exposure sum }\end{array}$ & 487 & 58 & 121 & 52 & 174 & 60 & 192 & 61 & 0.18 \\
\hline One & 275 & 31 & 62 & 23 & 96 & 32 & 118 & 35 & 0.02 \\
\hline Two & 355 & 46 & 93 & 47 & 134 & 49 & 128 & 42 & \\
\hline Three & 186 & 23 & 67 & 30 & 51 & 19 & 68 & 23 & \\
\hline \multicolumn{10}{|l|}{ Power hypothesis } \\
\hline \multicolumn{10}{|l|}{ Education } \\
\hline Lt high school & 108 & 15 & 51 & 25 & 20 & 8 & 37 & 14 & $<0.01$ \\
\hline High school graduate/GED & 196 & 25 & 61 & 28 & 64 & 24 & 71 & 25 & \\
\hline Some college or college graduate & 393 & 48 & 89 & 40 & 154 & 54 & 150 & 46 & \\
\hline Graduate school & 119 & 13 & 21 & 7 & 42 & 15 & 56 & 15 & \\
\hline \multicolumn{10}{|l|}{ Income } \\
\hline Lt $\$ 40,000$ & 345 & 41 & 105 & 48 & 104 & 35 & 136 & 42 & 0.20 \\
\hline$\$ 40,000-80,000$ & 249 & 31 & 64 & 28 & 93 & 34 & 92 & 30 & \\
\hline$\$ 80,000+$ & 149 & 99 & 31 & 15 & 61 & 23 & 57 & 18 & \\
\hline Missing & 73 & 9 & 22 & 10 & 22 & 9 & 29 & 10 & \\
\hline \multicolumn{10}{|l|}{ Social norms hypothesis } \\
\hline \multicolumn{10}{|l|}{ Neighborhood descriptive norm } \\
\hline All or most & 254 & 34 & 92 & 43 & 74 & 29 & 88 & 31 & 0.03 \\
\hline Some & 352 & 44 & 78 & 35 & 130 & 47 & 144 & 46 & \\
\hline Few or none & 191 & 23 & 50 & 22 & 66 & 24 & 75 & 23 & \\
\hline \multicolumn{10}{|l|}{ Family/peer descriptive norm } \\
\hline All or most & 120 & 15 & 37 & 16 & 36 & 14 & 47 & 16 & 0.72 \\
\hline Some & 221 & 28 & 69 & 31 & 69 & 26 & 83 & 28 & \\
\hline Few or none & 471 & 57 & 114 & 53 & 175 & 60 & 182 & 56 & \\
\hline Neighborhood injunctive norm & & & & & & & & & \\
\hline Acceptable & 130 & 18 & 27 & 14 & 49 & 20 & 54 & 18 & 0.12 \\
\hline Unacceptable & 157 & 20 & 36 & 19 & 47 & 16 & 74 & 25 & \\
\hline Don't care one way or the other & 478 & 62 & 146 & 67 & 166 & 64 & 166 & 57 & \\
\hline Family/peer injunctive norm & & & & & & & & & \\
\hline Acceptable & 126 & 17 & 44 & 22 & 42 & 16 & 40 & 13 & 0.009 \\
\hline Unacceptable & 344 & 43 & 70 & 34 & 111 & 40 & 163 & 51 & \\
\hline Don't care one way or the other & 327 & 40 & 101 & 43 & 122 & 44 & 104 & 35 & \\
\hline Control variables & & & & & & & & & \\
\hline Race/ethnicity & & & & & & & & & \\
\hline White & 358 & 43 & 65 & 28 & 127 & 45 & 166 & 52 & $<0.01$ \\
\hline Black & 219 & 26 & 74 & 34 & 80 & 28 & 65 & 20 & \\
\hline Hispanics/Latinos & 180 & 25 & 61 & 30 & 54 & 23 & 65 & 23 & \\
\hline Other & 40 & 6 & 14 & 8 & 12 & 4 & 14 & 5 & \\
\hline Smokers who quit since Jan 2002 & 71 & 9 & 16 & 6 & 20 & 7 & 35 & 12 & 0.02 \\
\hline Age (years) & & & & & & & & & \\
\hline $18-34$ & 262 & 35 & 65 & 33 & 86 & 34 & 111 & 39 & 0.11 \\
\hline $35-54$ & 390 & 46 & 110 & 47 & 150 & 51 & 130 & 40 & \\
\hline $55+$ & 161 & 19 & 45 & 20 & 44 & 15 & 72 & 41 & \\
\hline Marital status & & & & & & & & & \\
\hline Married & 260 & 38 & 69 & 39 & 96 & 38 & 95 & 36 & 0.75 \\
\hline Divorced, separated, widowed & 220 & 23 & 68 & 25 & 69 & 21 & 83 & 23 & \\
\hline Never married & 331 & 40 & 81 & 36 & 114 & 42 & 136 & 41 & \\
\hline Female & 366 & 43 & 94 & 40 & 130 & 46 & 142 & 44 & 0.44 \\
\hline
\end{tabular}


Table 2

Polychotomous regression model predicting high compared to low stigma and medium compared to low stigma $(N=816)$

\begin{tabular}{|c|c|c|c|c|c|c|}
\hline & \multicolumn{3}{|c|}{ High stigma compared to low stigma } & \multicolumn{3}{|c|}{ Medium stigma compared to low stigma } \\
\hline & $B$ & SE & $P$-value & $B$ & SE & $P$-value \\
\hline \multicolumn{7}{|l|}{ Attribution hypothesis } \\
\hline Smoking is due to weak character & 1.17 & 0.33 & $<0.01$ & -0.20 & 0.38 & 0.60 \\
\hline Smoking is due to bad genes & 0.63 & 0.39 & 0.11 & 0.07 & 0.40 & 0.85 \\
\hline Smoking is due to stress & 0.43 & 0.25 & 0.08 & 0.70 & 0.25 & $<0.01$ \\
\hline \multicolumn{7}{|l|}{ Fear hypothesis } \\
\hline Parent or primary caretaker & -0.59 & 0.26 & 0.02 & -0.42 & 0.23 & 0.09 \\
\hline Parents who smoke are a threat to their children & 0.64 & 0.24 & 0.01 & 0.43 & 0.24 & 0.06 \\
\hline \multicolumn{7}{|l|}{ Policy hypothesis } \\
\hline $\begin{array}{l}\text { Perceives one or more events of discrimination } \\
\text { Smoke free air exposure sum }\end{array}$ & 0.63 & 0.31 & 0.04 & -0.03 & & 0.92 \\
\hline One & Ref & Ref & Ref & Ref & Ref & Ref \\
\hline Two & -0.35 & 0.26 & 0.18 & -0.02 & 0.26 & 0.94 \\
\hline Three & -0.27 & 0.33 & 0.41 & -0.06 & -0.33 & 0.85 \\
\hline \multicolumn{7}{|l|}{ Power hypothesis } \\
\hline \multicolumn{7}{|l|}{ Education } \\
\hline Lt high school & Ref & Ref & Ref & Ref & Ref & Ref \\
\hline High school graduate/GED & 0.73 & 0.36 & 0.04 & 1.00 & 0.39 & 0.01 \\
\hline Some college or college graduate & 0.71 & 0.35 & 0.04 & 1.24 & 0.38 & $<0.01$ \\
\hline Graduate school & 1.02 & 0.48 & 0.04 & 1.50 & 0.50 & $<0.01$ \\
\hline \multicolumn{7}{|l|}{ Social norms hypothesis } \\
\hline \multicolumn{7}{|l|}{ Neighborhood descriptive norm } \\
\hline All or most & Ref & Ref & Ref & Ref & Ref & Ref \\
\hline Some & 0.22 & 0.27 & 0.40 & 0.29 & 0.27 & 0.29 \\
\hline Few or none & 0.14 & 0.31 & 0.65 & 0.27 & 0.33 & 0.42 \\
\hline \multicolumn{7}{|l|}{ Family/peer injunctive norm } \\
\hline Acceptable & Ref & Ref & Ref & Ref & Ref & Ref \\
\hline Unacceptable & 0.69 & 0.32 & 0.03 & 0.32 & 0.32 & 0.32 \\
\hline Don't care one way or the other & 0.26 & 0.32 & 0.42 & 0.40 & 0.31 & 0.19 \\
\hline \multicolumn{7}{|l|}{ Control variables } \\
\hline \multicolumn{7}{|l|}{ Race/ethnicity } \\
\hline White & Ref & Ref & Ref & Ref & Ref & Ref \\
\hline Black & -1.06 & 0.28 & $<0.01$ & -0.45 & 0.30 & 0.14 \\
\hline Hispanics/Latinos & -0.86 & 0.30 & $<0.01$ & -1.35 & 0.50 & $<0.01$ \\
\hline Other & -1.35 & 0.59 & 0.02 & -0.66 & 0.93 & 0.49 \\
\hline Smokers who quit since Jan 2002 & 0.39 & 0.37 & 0.28 & -0.18 & 0.40 & 0.65 \\
\hline
\end{tabular}

discrimination and stigma may be attenuated if former smokers who quit prior to NYC's tobacco control laws experienced less discrimination. Interestingly, exposure to smoke free air laws was not related to perceived stigma and thus, we doubt whether the results had we included all former smokers would be much different on this front. Third, to more fully understand the sources of smokerrelated stigma, it will be important to replicate this study using a multi-state and multi-city population-based sample. To assess the impact of social policies including media influences and smoke free air laws on smoker-related stigmatization it is important to assess whether there is interstate and intercity variation in perceptions of stigma. Furthermore, another potential source of stigma and discrimination not addressed in this study is the framing of tobacco control policies such as smoke free air laws as discriminatory, stigmatizing and an affront to smokers' civil rights by the tobacco industry. This is a factor we plan to investigate in future research. Fourth, some of the measures we used to test our hypotheses could be improved. Notably, our measure of "fear" does not assess fear directly, but rather, assesses a reason why people may fear smokers. A better assessment of fear would have directly queried respondents as to whether smokers are dangerous. Finally, because these data are cross-sectional we are unable to address issues of causality such as the possibility that perceived disapproval of smoking from family and peers is a response to stigma as opposed to a source of stigma.

\section{Smoker-related stigma and the U.S. tobacco epidemic}

Given the finding that individual attribution for smoking is related to smoker-related stigma it is important to understand how this factor came to be salient in the tobacco epidemic. An important milestone in the public health's movement against tobacco was the 1964 Surgeon General's report, which legitimized 15 years of growing evidence about the dangers of smoking to health. According to Brandt (1998), in response to this report, tobacco companies effectively presented the case for smoking as a voluntary risk. At the same time, Brandt argues, unlike many other western nations who had a direct stake in the health and disease of their populations due to the enactment of national health insurance programs, in the USA 
there was a strong disposition to hold individuals accountable for the risks they take.

Our data suggest that the theme that smoking is a voluntary risk continues to resonate today. While there are movements within the tobacco control community to reconstruct smoking behavior as influenced by external circumstances (Jarvis, 2004), our data suggest that these moves will not mitigate stigma and may in fact exacerbate it. It is possible that respondents who attribute smoking to stress perceive that it is the smoker's inability to manage stress that leads him/her to smoke and not the stress per say. Future research should probe more fully the extent to which smoking is perceived to be a socially determined behavior and whether such perceptions are related to stigma.

The severe health consequences for non-smokers from exposure to second hand smoke are well established thus, fear as a potential response, is understandable. For children and fetuses the health risks posed by second hand smoke are staggering including increased risk for low birth weight, sudden infant death syndrome, lung infections and asthma. Furthermore, research shows that children whose parents smoke are twice as likely to smoke themselves (US Department of Health and Human Services, 2001). We are unable to discern in this study whether the stigma stems from fear about the harms of the second hand smoke per se or from the construction of children as innocent victims who are exposed to their parent's "reckless" smoking. We suspect it is some combination of both. We also suspect that fear will be an even greater determinant of stigmatized attitudes towards smokers in nonsmoking populations.

We documented a strong relationship between experiences of structural discrimination and perceptions of smoker-related stigma. While Americans have long accepted that employers have a certain degree of control over what they do while at the workplace, increasing numbers of employers are broadening the sphere of their control to include what employees do in their own homes. While there is no comprehensive list of companies which practice lifestyle discrimination in the USA, according to a 1988 survey taken by the Administrative Management Society, 6\% of all employers then discriminated against off-duty smokers (National Workrights Institute, 2006). This percentage is now likely much higher. Recently, the World Health Organization became the largest international employer to ban the hiring of smokers in an effort to promote its public health campaign against tobacco use (Glantz, 2005). We note that discrimination against smokers is likely to increase because most states have not yet passed laws barring forms of lifestyle discrimination in the USA (National Workrights Institute, 2006).

It can be argued that what we are calling experiences of discrimination do not qualify as such, but rather are justified responses because of the harms second hand smoke poses to non-smokers as well as the economic burden that smoking imposes on employers and societies. For example, one of the driving forces behind the trend to not hire and to fire smokers is the rising health care costs of employers leading some employers to charge employees who smoke more for their health insurance. Concerns about the harms of second hand smoke in multiple occupant rental properties and the economic burdens of smoking to landlords may also provide a justification for discrimination in rental properties. It should further be mentioned that the tobacco industry has been instrumental in the framing of these sorts of experiences as discriminal. It is beyond the scope of this study to deliberate whether these policies to sanction smokers are justified.

The hypothesis that exposure to smoke free air laws would be associated with smoker-related stigma was not supported by these data. It is important to draw attention to this null finding because it suggests that it may be possible to create policies that alter the social norms around smoking without contributing to the stigmatization of individual smokers.

While substantial progress has been made in reducing the prevalence of smoking in the last few decades, smoking rates are different across socioeconomic groups (Centers for Disease Control, 2004). Education is the strongest predictor of smoking patterns (Barbeau et al., 2004; Escobedo \& Peddicord, 1996). Several factors have been proposed to explain the link between education and smoking. For example, one explanation pertains to differential patterning of normative environments by education level. Another is that persons with more education are exposed to more smoke free air laws (Barbeau et al., 2004). The association we document between educational level and smoker-related stigma is consistent with an explanation that the social unacceptability of smoking, which is likely the function of several different mechanisms at play simultaneously, has a greater impact on smoking patterns among more highly educated smokers as compared to less educated smokers. Stigma is one potential mechanism underlying the social unacceptability that contributes to educational disparities in smoking.

Our finding that family and friends' disapproval of smoking behavior is related to smoker-related stigmatization, whereas descriptive norms are not related to stigma is not surprising when considered within the context of other influential behavioral theories such as the Ajzen and Fishbein's (1973) Theory of Reasoned Action (TRA). According to the TRA, when deciding on a course of action, people reflect upon the beliefs of what other people expect them to do. It is possible that stigma is a mediator in the relationship between these expectations and smoking behavior. Given that stigmatization is fundamentally a process of devaluation and exclusion, it makes sense that normative evaluations as opposed to observational evaluations would be the most pertinent to stigma formation processes. Currently, research on social norms in the smoking literature and on the relationship between social norms and stigma is languishing. While much more research is needed, this study begins to advance this agenda.

The finding that Blacks and Latinos perceive less smoker-related stigma than Whites was not anticipated. We did not formulate an a priori hypothesis about this relationship because the differences between racial and ethnic groups in terms of smoking prevalence are not clear cut. For example, Asians and Latinos tend to smoke less than Whites although this gap is quickly narrowing and there is variation in tobacco prevalence within subpopulations depending on the country of origin, gender 
and time acculturated in the USA (NSDUH, 2006). Since 1965, the reported prevalence of smoking among Blacks has exceeded that among Whites especially, among Black men living in cities, and the reported prevalence of quitting is less for Blacks than for Whites (Novotny, Warner, Kendrick, \& Remington, 1988). Explanations for racial and ethnic differences in smoking prevalence tend not to emphasize differences in perceived social unacceptability of smoking. In fact, when social unacceptability is considered a plausible mechanism underlying differences in tobacco prevalence among different racial and ethnic groups, it is often believed that these groups are less accepting of tobacco use than Whites (Royce, Hymowitz, Corbett, Harwell, \& Orlandi, 1993). So, why might Black and Latino respondents in this study perceive less smoker-related stigma than the White respondents (which would suggest they may be more accepting of tobacco use)?

One possibility is that this is a segregation effect or a reflection of greater exposure to destigmatizing influences. Compared to the rest of the nation, New York City is a relatively segregated city (Beveridge, 2002). It is possible that tobacco control policies are more weakly enforced in segregated neighborhoods or alternatively, that counter stigmatizing effects such as tobacco industry advertising diminish stigma. Studies have demonstrated that the tobacco industry markets their products more aggressively in lower income highly segregated neighborhoods (Stoddard, Johnson, Sussman, Dent, \& Boley-Cruz, 1998). We tested whether the association between race/ethnicity and stigma was explained when we include a variable measuring the degree of neighborhood segregation (as measured by the percentage of residents in each of NYC's 39 community districts who are Black or Hispanic). What we find is that respondents who live in more segregated neighborhoods perceive less smoker-related stigma. However, this association was attenuated in the presence of individual race/ethnicity. This suggests that there is not only a segregation effect underlying Blacks and Latinos perceptions of smoker-related stigmatization, but also that Blacks and Latinos perhaps because they perceive stigma and discrimination related to their racial identity may be more likely to discount the existence of smoker-related stigma. Future research should continue to investigate the role of smoker-related stigma in the production of racial and ethnic smoking disparities.

\section{Conclusion}

Many of the sources of smoker-related stigma identified in this study are malleable. The tobacco control community should address the role of stigmatization in the epidemic and decide if it is something it wants to promote or discourage. A potential benefit of smoker-related stigma is that it may lead people to quit (or dissuade people from taking up smoking to begin with) (Stuber, Galea, \& Link, submitted for publication) making it important to undertake studies such as this one, which seek to more fully understand the sources of this powerful force. We found that the construction of smoking as a voluntary behavior, messages that blame the smoker for harming innocent victims such as children, structural forms of discrimination, and disapproval of smoking behavior expressed by family and peers all contribute to smoker-related stigma. Importantly, these findings suggest that the deterrent effects of stigma may not be experienced equally across different socioeconomic and racial/ethnic subgroups and highlights the need to understand stigma processes in the smoking epidemic more fully.

\section{References}

Ajzen, \& Fishbein. (1973). Attitudinal and normative variables as predictors of specific behaviors. Journal of Personality and Social Psychology, 27, 41-57.

American Lung Association. (2007). State laws restricting smoking. $<$ http://slati.lungusa.org/reports.asp $>$.

Alamar, B., \& Glantz, S. (2006). Effect of increased social unacceptability of cigarette smoking on reduction in cigarette consumption. American Journal of Public Health, 96(8), 1359-1362.

American Civil Liberties Union. (1998). Introduction to lifestyle discrimination in the workplace. < http://www.aclu.org/workplacerights/gen/ 13388res19981231.html $>$ Accessed 25.05.06.

Bainson, K. A., \& Van den Borne, B. (1998). Dimensions and processes of stigmatization in leprosy. Leprosy Review, 69(4), 341-350.

Barbeau, E. M., Krieger, N., \& Soobader, M. J. (2004). Working class matters: socioeconomic disadvantage, race/ethnicity, gender and smoking in NHIS 2000. American Journal of Public Health, 94(2), 269-278.

Beveridge, A. (2002). Segregation. Gotham Gazette: New York City News and Policy. <http://www.gothamgazette.com/article/20020301/5/ 594 > Accessed 25.05.06.

Braithwaite, J. (1989). Crime, shame and reintegration. Cambridge: Cambridge University Press.

Brandt, A. M. (1998). Blow some smoke my way: passive smoking, risk and American culture. In S. Lock, L. Reynolds, \& E. M. Tansey (Eds.), Ashes to ashes: The history of smoking and health. Amsterdam/Atlanta, GA: Rodope B.V.

Brownson, R. C., Eriksen, M. P., Davis, R. M., \& Warner, K. E. (1997). Environmental tobacco smoke: health effects and policies reduce exposure. Annual Review of Public Health, 18, 163-185.

Centers for Disease Control. (2004). Cigarette smoking among adults. Morbidity and Mortality Weekly Report, 53(20), 427-431.

Cialdini, R. B., Kallgren, C. A., \& Reno, R. R. (1991). A focus theory of normative conduct. Advances in Experimental Social Psychology, 24, 201-234.

Comrey, A. L., \& Lee, H. B. (1992). A first course in factor analysis, (2nd ed.). Hillsdale, NJ: Lawrence Erlbaum Associates.

Corrigan, P., Markowitz, F. E., Watson, A., Rowan, D., \& Kubiak, M. A. (2003). An attribution model of public discrimination towards persons with mental illness. Journal of Health and Social Behavior, 44, 162-179.

Corrigan, P. W. (2000). Mental health stigma as social attribution: implications for research methods and attitude change. Clinical Psychology: Science and Practice, 7, 48-67.

Erikson, K. T. (1966). Wayward Puritans: A study in the sociology of deviance. Wiley.

Escobedo, L. G., \& Peddicord, J. P. (1996). Smoking prevalence in US birth cohorts: the influence of gender and education. American Journal of Public Health, 86, 231-236.

Fichtenberg, C. M., \& Glantz, S. A. (2002). Effect of smoke-free workplaces on smoking behavior: systematic review. British Medical Journal, 325(7357), 188-196.

Fishbein, M., \& Ajzen, I. (1975). Belief, attitude, intention and behavior: An introduction to theory and research. MA: Addison-Wesley.

Frieden, T., Mostashari, F., Kerker, B., Miller, N., Hajat, A., \& Frankel, M. (2005). Adult tobacco use levels after intensive tobacco control measures. American Journal of Public Health, 95(6), 1016-1023.

Galea, S., Vlahov, D., Resnick, H., Ahern, J., Susser, E., \& Gold, J., et al. (2003). Trends in probable posttraumatic stress disorder in New York City after the September 11 terrorist attacks. American Journal of Epidemiology, 158(6), 514-524.

Gilpin, E. A., Lee, L., \& Pierce. (2004). Changes in population attitudes about where smoking should not be allowed: California versus the rest of the USA. Tobacco Control, 13, 38-44.

Glantz, L. (2005). Smoke got in their eyes. Washington Post, December 18, B07.

Goffman, E. (1963). Stigma: Notes on the management of spoiled identity. New York: Simon \& Schuster Inc. 
Herek, G. M., Capitanio, J. P., \& Widaman, K. F. (2002). HIV-related stigma and knowledge in the United States: prevalence and trends, 1991-1999. American Journal of Public Health, 83, 574-577.

Jarvis, M. J. (2004). ABC of smoking cessation: why people smoke. British Medical Journal, 328(31), 277-279.

Link, B. G., Cullen, F. T., Frank, J., \& Wozniak, J. (1987). The social rejection of former mental patients: understanding why labels matter. American Journal of Sociology, 92(6), 1461-1500.

Link, B. G., \& Phelan, J. C. (2001). Conceptualizing stigma. Annual Review of Sociology, 27, 363-385.

Link, B. G., Phelan, J. C., Bresnahan, M., Stueve, A., \& Pescosolidio, B. (1999). Public conceptions of mental illness: labels, causes, dangerousness, and social distance. American Journal of Public Health, 89(9), 1328-1333.

National Survey on Drug Use and Health. (2006). Past month cigarette use among racial and ethnic groups. The NSDUH Report, Vol. 30.

National Workrights Institute. (2006). Lifestyle discrimination in the workplace. < http://www.workrights.org/issue_lifestyle/ld_legislative_ brief.html $>$ Accessed 08.08.06.

Novotny, T. E., Warner, K. E., Kendrick, J., \& Remington, P. L. (1988) Smoking by Blacks and Whites: socioeconomic and demographic differences. American Journal of Public Health, 78(9), 1187-1189.

Pampel, F. C. (2006). Socioeconomic distinction, cultural tastes and cigarette smoking. Social Science Quarterly, 87(1), 19-35.

Phelan, J. C. (2005). Geneticization of deviant behavior and consequences for stigma: the case of mental illness. Journal of Health and Social Behavior, 46, 307-322.
Royce, J., Hymowitz, N., Corbett, K., Hartwell, T. D., \& Orlandi, M. A. (1993) Smoking cessation factors among African Americans and Whites American Journal of Public Health, 82(2), 220-226.

Schneider, A., \& Ingram, H. (1993). Social construction of target populations: implications for politics and policy. American Political Science Review, 87(2), 334-347.

Sorenson, G., Emmons, K., Stoddard, A., \& Linnan, L. (2002). Do social influences contribute to occupational differences in smoking behavior? American Journal of Public Health, 16(3), 135-141.

Stoddard, J. L., Johnson, C. A., Sussman, S., Dent, C., \& Boley-Cruz, T. (1998). Tailoring outdoor tobacco advertising to minorities in Los Angeles County. Journal of Health Communication, 3(2), 137-146.

Stuber, J., Galea, S., \& Link, B. Stigma and smoking: the consequences of our good intentions. Journal of Health and Social Behavior, submitted for publication.

US Department of Health and Human Services. (1999). Health effects of exposure to environmental tobacco smoke: The report of the California Environmental Protections Agency. [Smoking and Tobacco Control Monograph No. 10]. Bethesda, MD: National Institutes of Health, National Cancer Institute.

US Department of Health and Human Services. (2001). Changing adolescent smoking prevalence. Smoking and Tobacco Control Monograph, 14, 85-89.

Weiner, B. (1995). Judgments of responsibility: A foundation for a theory of social conduct. New York: Guilford Press.

Zickler, P. (2006). Evidence builds that genes influence cigarette smoking. NIDA NOTES, 15(2). < http://www.drugabuse.gov/NIDA_Notes/ NNVol15N2/Evidence.html $>$ Accessed August 4. 